\title{
Is the healthy start scheme associated with increased food expenditure in low-income families with young children in the United Kingdom?
}

\author{
Jennie Parnham ${ }^{1 *}$ (D), Christopher Millett ${ }^{1}$, Kiara Chang ${ }^{1}$, Anthony A. Laverty ${ }^{1}$, Stephanie von Hinke ${ }^{2,3,4}$,
} Jonathan Pearson-Stuttard ${ }^{5,6,7,8}$ and Eszter P. Vamos ${ }^{1}$

\begin{abstract}
Background: Healthy Start is a food assistance programme in the United Kingdom (UK) which aims to provide a nutritional safety-net and enable low-income families on welfare benefits to access a healthier diet through the provision of food vouchers. Healthy Start was launched in 2006 but remains under-evaluated. This study aims to determine whether participation in the Healthy Start scheme is associated with differences in food expenditure in a nationally representative sample of households in the UK.

Methods: Cross-sectional analyses of the Living Costs and Food Survey dataset (2010-2017). All households with a child (0-3years) or pregnant woman were included in the analysis $(n=4869)$. Multivariable quantile regression compared the expenditure and quantity of fruit and vegetables (FV), infant formula and total food purchases. Four exposure groups were defined based on eligibility, participation and income (Healthy Start Participating, Eligible Nonparticipating, Nearly Eligible low-income and Ineligible high-income households).

Results: Of 876 eligible households, 54\% participated in Healthy Start. No statistically significant differences were found in FV or total food purchases between participating and eligible non-participating households, but infant formula purchases were lower in Healthy Start participating households. Ineligible higher-income households had higher purchases of FV.
\end{abstract}

Conclusion: This study did not find evidence of an association between Healthy Start participation and FV expenditure. Moreover, inequalities in FV purchasing persist in the UK. Higher participation and increased voucher value may help to improve programme performance and counteract the harmful effects of poverty on diet.

Keywords: Healthy start vouchers, Nutrition assistance programmes, Public health nutrition, public health policy evaluation

*Correspondence: j.parnham18@imperial.ac.uk

1 Department of Primary Care, Public Health Policy Evaluation Unit,

School of Public Health, Imperial College London, Charing Cross Campus,

St Dunstans Road, London W6 8RP, UK

Full list of author information is available at the end of the article

\section{Background}

Individuals in the UK from higher socioeconomic positions (SEP) are $80 \%$ more likely than those from lower socioeconomic positions to eat the recommended amount of fruit and vegetables (FV) a day [1]. However, it is notable that even in the higher SEP group only one in four meet the recommendation. As diet is one of the 
leading risk factors for non-communicable disease morbidity and mortality, inequalities in dietary intake contribute to health inequalities in the UK [2]. The cost of a healthy diet is proposed as a key factor among the complex and multifaceted determinants of socioeconomic inequality in diets [3-5]. Moreover in recent years, the price of $\mathrm{FV}$ has increased disproportionately relative to nutrient-poor, energy-dense foods [6, 7], serving to exacerbate the financial barrier to a healthy diet.

The UK's Healthy Start scheme was introduced in 2006 by the Department of Health and Social Care, with a stated aim of providing a nutritional safety net and improving the access to a healthy diet for low-income families $[8,9]$. This UK-wide statutory scheme entitles low-income families with a pregnant woman or child aged 0-3years to receive vouchers which can be redeemed for FV, cow's milk and infant formula (see Table S1 for details). The vouchers were worth $£ 3.10$ / week per pregnant woman and child aged 1-3years and $£ 6.20$ /week per child under 1 year. In England, the voucher value had not changed since 2010, however in April 2021 the value increased to $£ 4.25$ /week [10]. There are roughly 500,000 eligible beneficiaries in England, but uptake has been declining from $73 \%$ in 2015 to $51 \%$ in 2020 [11]. One reason for this is that access to the scheme is not automatic, beneficiaries must apply. As the promotion of Healthy Start is the responsibility of local public health teams and health professionals, awareness of the scheme varies between regions [12]. Moreover, beneficiaries have stated barriers in the application process, such as the need for a health professional to sign the application [13, 14]. Consequently, uptake is strongly determined by health professionals signposting participants in pre- and post-natal healthcare appointments [15].

Qualitative evaluations have found that Healthy Start vouchers were valued by recipients and helped reduce the experience of food insecurity [13, 14, 16]. However, the only two existing large-scale quantitative evaluations of Healthy Start are in contradiction; reporting a null effect on FV intake [17] and positive effect on FV purchasing [18], respectively. These two previous evaluations used eligibility, not participation, as the exposure variable. Not all eligible households participate in Healthy Start [12]. It is currently unknown which household characteristics are associated with participation in Healthy Start. Moreover, there is no evidence on whether participation is associated with different spending within the eligible population. It is important for policy makers to understand if Healthy Start reaches its target population and whether it is effective at improving the nutrition of low-income families.
This paper aims to determine whether Healthy Start participation is associated with differences in purchasing of $\mathrm{FV}$, infant formula and total food purchases among households who are Healthy Start participants, eligible non-participants, nearly eligible non-participants and ineligible non-participants.

\section{Methods}

\section{Data source and study participants}

The Living Costs and Food Survey (LCFS) is an annual cross-sectional survey of UK households which collects detailed income, expenditure and sociodemographic data [19]. The sample is a multi-stage stratified random sample with clustering, selected from a register of postcodes in the UK [20]. Full details of survey methodology are reported elsewhere [20]. Participating households were surveyed at home by a trained interviewer and instructed to complete a two-week expenditure diary collecting the expenditure and quantity of purchases. LCFS measured Healthy Start participation from 2010 onwards. Due to low annual sample size of participating households, a cross-sectional study design was used, pooling years 2010-2017.

\section{Analytic sample}

All households with a pregnant woman or child 0-3 years were included in the analytic sample, in congruence with the Healthy Start eligibility criteria (see Table S1). Healthy Start vouchers are dispensed at the household level, so the household was used as the unit of analysis. There was a total of 42,034 households surveyed across years 2010-2017 in the LCFS. Households without a child $0-3$ years or pregnant woman $(n=37,147)$ and households with missing data $(n=25)$ were excluded, leaving 4869 households in the study.

\section{Exposure groups}

Data on income and welfare benefits were collected through interview and confirmed through official documentation (e.g. payslips). Income was equivalised using OECD scales to account for the effect of household size and composition on expenditure [20]. All the households in the study sample had a household member who would qualify for Healthy Start by their age or pregnancy status, thus income-level was used to stratify the exposure groups.

Households were categorised as eligible for Healthy Start if they received a qualifying income-related welfare benefit (see Table S1). This group was further divided by participation in the Healthy Start scheme. The remaining households did not receive a qualifying benefit, therefore were ineligible for Healthy Start. Ineligible households were also divided into two groups, low- and high-income 
households. Households were defined as low-income if they had an income less than $60 \%$ of the median disposable income that year, after adjustment for inflation [21]. The low-income group represented households who just missed out on welfare schemes but were still at a high risk of experiencing food insecurity. The high-income group was included to explore and quantify differences in household expenditure across the socioeconomic gradient.

In summary, the four exposure groups derived were:

1. Healthy Start Eligible Participants; households who received an income-related welfare benefit and reported receiving Healthy Start vouchers.

2. Healthy Start Eligible Non-participants; households who received an income-related welfare benefit but did not report receiving Healthy Start vouchers.

3. Nearly Eligible Non-participants; households defined as low-income but did not receive benefits.

4. Ineligible Non-participants; households who were neither low-income nor received benefits.

\section{Outcome variables}

Expenditure and quantity of all purchases were recorded in a two-week expenditure diary, confirmed by receipts. Analysis using quantity variables as outcomes were restricted to years 2010-2015 as later data on quantity of purchases have not yet been released. Both the expenditure and quantity of food purchases were used as outcomes to explore whether households chose different priced products within the same category. For example, low-income households are more likely to be price sensitive [22], and therefore may choose FV which are lower in cost, but not volume. This is important as only differences in the quantity of food purchased have important implications for health. It would be interesting to explore the types of FV spending, but the analysis lacked statistical power to differentiate spending at such low levels.

The following variables were used as outcome variables, all averaged across 1 week per household: (i) FV expenditure ( $£$ /week); (ii) Healthy Start qualifying foods (fresh or frozen FV, cow's milk and infant formula) expenditure ( $($ / week); (iii) infant formula expenditure ( $£$ /week); (iv) total food expenditure ( $£$ /week); (v) FV quantity (kg/week) and (vi) Healthy Start foods quantity (kg/week). The outcome variables are guided by.

\section{Covariates}

Covariates included survey year, survey quarter, household size, number of children in the household, age of household reference person (HRP)(years), ethnicity of HRP (White or Ethnic Minority), National Statistics
Socioeconomic Classification (NS-SEC) social class (higher professional occupations, intermediate occupations, routine and manual occupations and unemployed or students), age HRP completed full-time education (<16 years; $16-18$ years and $>18$ years) and region (North, Midlands, East, London, South, Wales, Scotland and Northern Ireland).

\section{Statistical analysis}

To account for inflation, income and expenditure variables were adjusted using category specific Consumer Price Indices, using 2017 as the base year [23]. Indicators for survey year and quarter were included to control for macroeconomic differences across time. Survey weights, generated by LCFS, were used in all analyses to account for non-response bias and to produce results representative to the population [20]. Analyses using infant formula as an outcome were performed on a subsample of households with a child less than one-year old $(n=1260)$, as the vouchers may only be redeemed for infant formula for this age-range.

Differences in characteristics across groups were compared using $X^{2}$ for categorical variables, student $t$-test and analysis of variance for normally distributed variables, and Mann-Whitney and Kruskal-Wallis test for skewed continuous variables, as appropriate (See Table 1 for details).

Multivariable quantile regression was used to assess differences in each outcome between the four exposure groups, using Healthy Start Eligible Non-participants as the reference group. Since outcomes were positively skewed, quantile regression estimates the median (or other percentile) of outcome distribution instead of the mean and is therefore less sensitive to the influence of outliers [24]. Quantile regression also allows for the effects of the covariates to differ at different points of the outcome distribution. Results are presented for the 25th, 50 th and 75th percentiles of the outcome variable.

Ordinary least squares (OLS) regression was also performed and presented alongside results of the quantile regression as a comparison between the two methods and check for robustness. Wald tests were performed to test for equality between Nearly Eligible and Ineligible coefficients at the 25th, 50th and 75th percentile. Multicollinearity was tested by calculating variation inflation factors $(\mathrm{VIF})$, all values were below $10(\max \mathrm{VIF}=1.51)$ indicating no evidence for multicollinearity.

Covariates were added into the regression models in a stepwise manner. Model 1 adjusted for survey year and survey quarter. Model 2 additionally included household size, number of children and age of HRP. Model 3 additionally included ethnicity of HRP, NS-SEC social class, age HRP completed full-time education and region. 


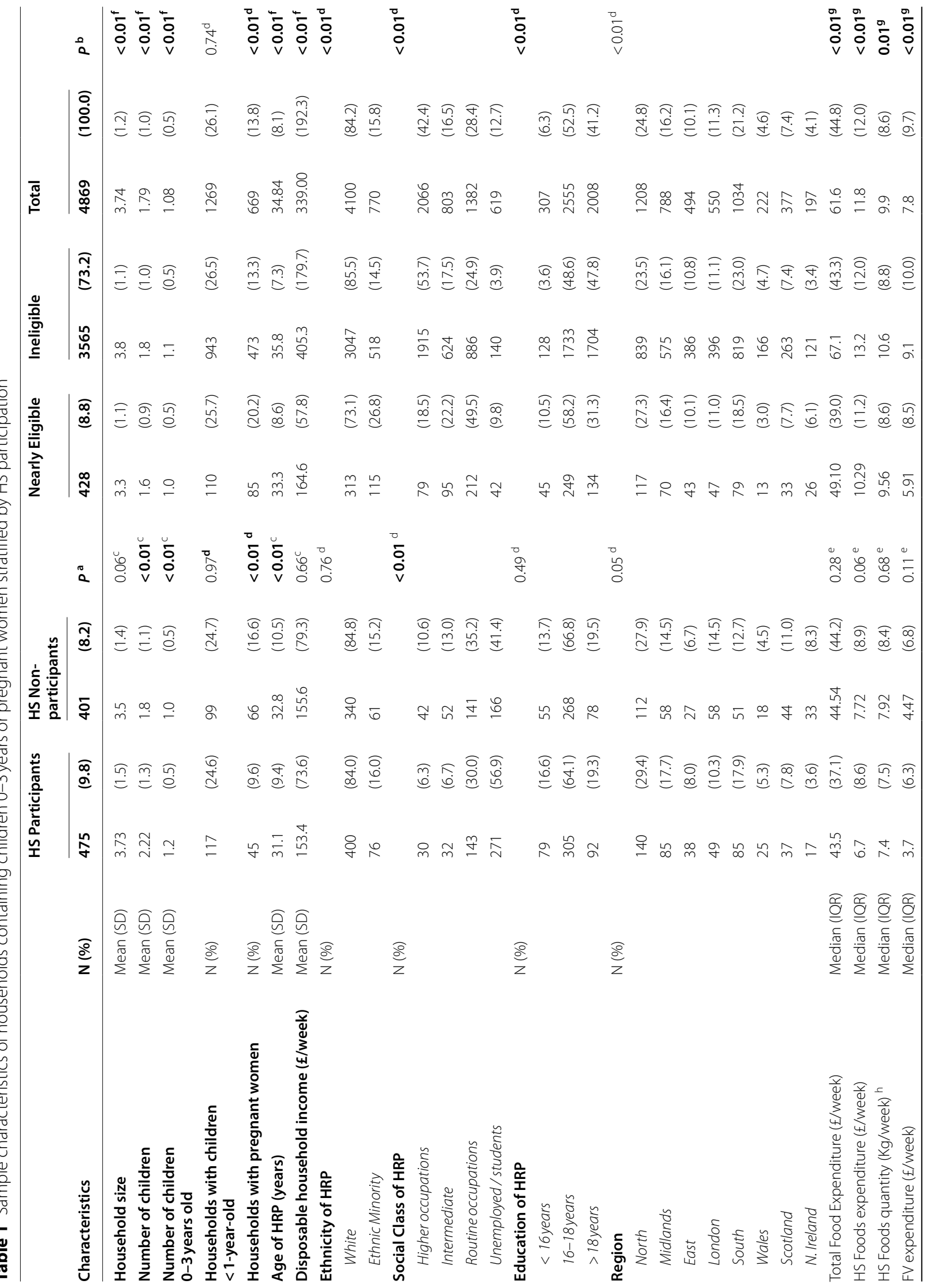




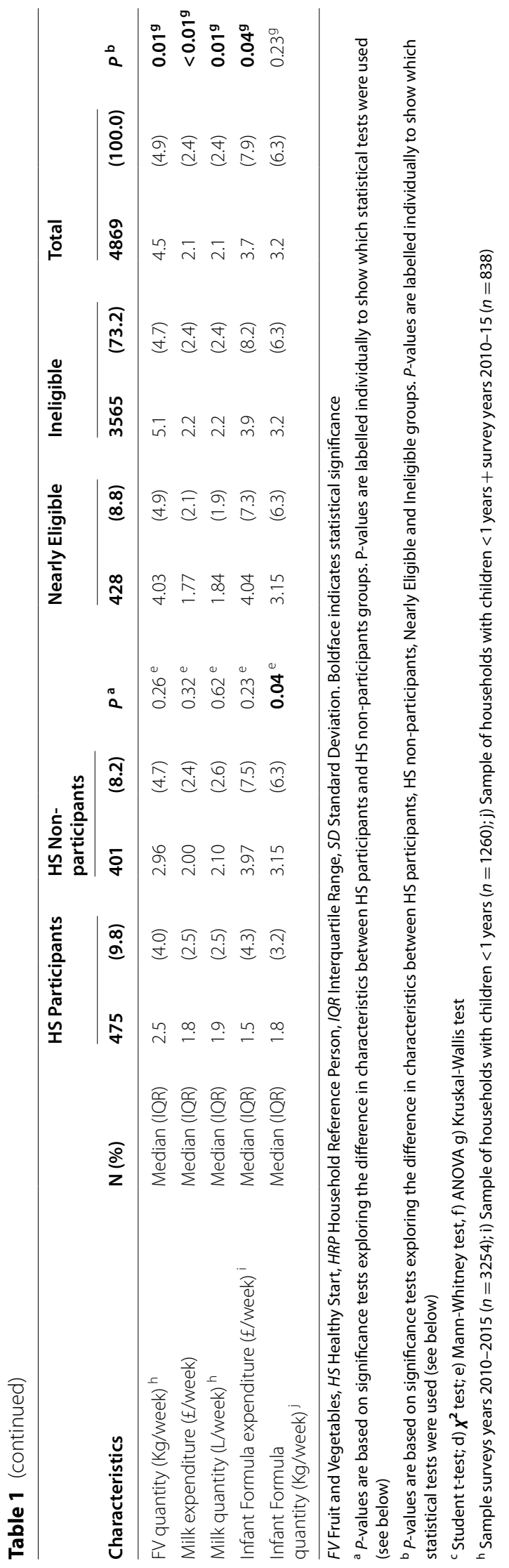


For sensitivity analyses, the same descriptive analyses and quantile regressions on expenditure outcomes were performed after excluding participants without quantity of food purchases data (2015-2017).

Stata V.15 (StataCorp) was used to perform all descriptive and inference tests, using a 95\% confidence level for significance.

\section{Results}

Table 1 presents the characteristics of the analytic sample. A total of 876 households were eligible for Healthy Start, of these, $54 \%(n=475)$ reported participating in Healthy Start and $46 \%(n=401)$ households were Eligible Non-participants. Healthy Start Participants and Eligible Non-participants had similar mean income level, ethnicity and education, but participants were more likely to be in a lower social class and have young children but were less likely to have a pregnant woman than Eligible Non-participants. Households which were ineligible for Healthy Start were found to be older and have a higher occupation, education and income levels than eligible households.

Results of the median quantile regression of FV, Healthy Start foods, infant formula and total food expenditure across the four exposure groups are displayed in Table 2. In the minimally adjusted model, a significant lower purchase of FV and HS foods was observed in Healthy Start Participants compared to Eligible Non-participants. However, differences did not persist. In the fully adjusted models, there was no statistically significant difference between Healthy Start Participants and Eligible Non-participants in FV, Healthy Start food or total food expenditure. Infant formula purchases were significantly lower in Healthy Start Participants $(-1.82 £$ /week; 95\% CI -3.12, - 0.51). These results were consistent when quantity variables were analysed (Table S2). Cow's milk was tested as an outcome but there was no difference in expenditure across all groups (Table 2). Nearly Eligible and Ineligible households, however, were observed with higher FV and Healthy Start food expenditure than Eligible Non-participants. For total food expenditure, only Ineligible households had significantly higher spending compared to Eligible Non-participants (7.30£/week; 95\% CI 3.06, 11.53).

We additionally assessed the differences in outcome at the 25th and 75th percentile using quantile regression across the four exposure groups. This is important as the difference in spending between Healthy Start Eligible, Nearly Eligible and Ineligible households differed across the expenditure distribution. For example, the non-significant differences in FV expenditure between Healthy Start Participants and Eligible Non-participants were observed consistently at the 25th, 50th and 75th percentile (Fig. 1.A). However, differences in FV expenditure of Nearly Eligible and Ineligible compared to Healthy Start Eligible Non-participants increased between the 25th and 75th percentile of FV expenditure (Fig. 1.A). This implies that the more ineligible households spent on FV, the greater the magnitude of difference compared to Healthy Start Eligible Non-participating households. Importantly, a similar pattern was not seen for FV quantity. The coefficients were of consistent magnitude across all percentiles assessed (Fig. 1.B). This indicates that the higher levels of expenditure observed did not correspond to a higher quantity of FV purchased.

Sensitivity analyses demonstrated that results were robust when using a complete case analysis (Table S2 and S3).

\section{Discussion}

Using nationally representative data, the present analysis did not find evidence of an association between Healthy Start participation and the purchase of FV, Healthy Start foods or total foods. An inequality in purchases was observed as FV expenditure was higher in both Nearly Eligible and Ineligible households, compared to Healthy Start Participants or Eligible Non-participants. Total food expenditure was higher only in Ineligible households.

No previous evaluation of the scheme has compared the impact of the Healthy Start programme within an eligible population. Griffith et al. [18] used a difference-indifferences analysis of household purchase data 2 years before and after programme implementation, reporting a $£ 2.43 /$ month ( $£ 0.61 /$ week) increase in FV spending in Healthy Start eligible households compared to ineligible low-income households with a child aged 4-8years. Scantlebury et al. [17] compared FV intake among adults and children aged 5 years or over from Healthy Start eligible and ineligible households in England, but reported no association between Healthy Start eligibility and individual $\mathrm{FV}$ intake following programme introduction. The present finding adds to the current evidence base, indicating that it is unlikely that Healthy Start vouchers had a discernible impact on the dietary behaviours of its target population, for the study period. In lieu of an experimental design, our study has used the most appropriate control group, eligible non-participants, to evaluate the effect of the voucher.

By contrast, a similar food assistance programme in the United States has demonstrated greater success. The Special Supplemental Nutrition Program for Women, Infants and Children (WIC) serves low-income families with pregnant women or children aged 0-5years at risk of nutritional deficiencies. However, alongside distributing cash-value vouchers for FV, WIC additionally provides healthy food packages (i.e. low-fat milk, wholemeal bread, and legumes, see details in Table S1). Despite 
Table 2 Median regression of HS participation on food expenditure in LCFS (years 2010-2017, n=4870)

\begin{tabular}{|c|c|c|c|c|c|c|}
\hline & \multicolumn{2}{|l|}{ Model 1} & \multicolumn{2}{|l|}{ Model 2} & \multicolumn{2}{|l|}{ Model 3} \\
\hline & Coef. & $(95 \% \mathrm{Cl})$ & Coef. & $(95 \% \mathrm{Cl})$ & Coef. & $(95 \% \mathrm{Cl})$ \\
\hline \multicolumn{7}{|c|}{ FV expenditure ( $£ /$ week) } \\
\hline HS Participants & $-0.89 *$ & $(-1.67,-0.10)$ & -0.25 & $(-0.80,0.29)$ & 0.37 & $(-0.37,1.11)$ \\
\hline HS Non-participants & - & - & - & - & - & - \\
\hline Nearly Eligible & $1.56^{* *}$ & $(0.49,2.63)$ & $1.40^{* *}$ & $(0.49,2.31)$ & $1.14^{*}$ & $(0.18,2.09)$ \\
\hline Ineligible & $4.56^{* * *}$ & $(3.88,5.23)$ & $3.55^{* * *}$ & $(2.91,4.18)$ & $2.22 * * *$ & $(1.57,2.86)$ \\
\hline \multicolumn{7}{|c|}{ HS food expenditure ( $£ /$ week) } \\
\hline HS Participants & $-1.14^{*}$ & $(-2.27,-0.00)$ & -0.64 & $(-1.48,0.20)$ & -0.07 & $(-0.85,0.71)$ \\
\hline HS Non-participants & - & - & - & - & - & - \\
\hline Nearly Eligible & $2.05^{* *}$ & $(0.81,3.29)$ & $1.96 * * *$ & $(0.84,3.09)$ & $1.60 * * *$ & $(0.79,2.41)$ \\
\hline Ineligible & $5.11 * * *$ & $(4.26,5.97)$ & $3.69 * * *$ & $(2.86,4.51)$ & $2.56^{* * *}$ & $(1.77,3.35)$ \\
\hline \multicolumn{7}{|c|}{ Infant formula expenditure ( $£ /$ week $)^{a}$} \\
\hline HS Participants & $-3.07^{* * *}$ & $(-4.80,-1.35)$ & $-2.73^{* *}$ & $(-4.51,-0.94)$ & $-1.82^{* *}$ & $(-3.12,-0.51)$ \\
\hline HS Non-participants & - & - & - & - & - & - \\
\hline Nearly Eligible & -0.53 & $(-1.76,0.70)$ & -0.61 & $(-1.95,0.73)$ & -0.54 & $(-1.91,0.83)$ \\
\hline Ineligible & -0.44 & $(-1.49,0.61)$ & -0.35 & $(-1.52,0.82)$ & -0.83 & $(-2.04,0.38)$ \\
\hline \multicolumn{7}{|c|}{ Total food expenditure ( $(\mathfrak{f} /$ week) } \\
\hline HS Participants & -0.31 & $(-5.99,5.37)$ & -4.11 & $(-9.46,1.25)$ & -1.39 & $(-5.72,2.95)$ \\
\hline HS Non-participants & - & - & - & - & - & - \\
\hline Nearly Eligible & 4.52 & $(-0.02,9.06)$ & 1.61 & $(-3.97,7.19)$ & 2.65 & $(-2.19,7.48)$ \\
\hline Ineligible & $21.85^{* * *}$ & $(17.58,26.13)$ & $13.43^{* * *}$ & $(8.69,18.18)$ & $7.30^{* * *}$ & $(3.06,11.53)$ \\
\hline \multicolumn{7}{|c|}{ Cow's milk expenditure ( $£$ /week) } \\
\hline HS Participants & -0.24 & $(-0.53,0.04)$ & -0.25 & $(-0.53,0.02)$ & -0.17 & $(-0.43,0.09)$ \\
\hline HS Non-participants & - & - & - & - & - & - \\
\hline Nearly Eligible & -0.2 & $(-0.49,0.08)$ & -0.15 & $(-0.35,0.06)$ & -0.21 & $(-0.46,0.03)$ \\
\hline Ineligible & 0.14 & $(-0.11,0.39)$ & -0.02 & $(-0.22,0.18)$ & -0.18 & $(-0.41,0.05)$ \\
\hline
\end{tabular}

LCFS Living Costs and Food Survey, CI Confidence interval, FV Fruit and Vegetables, HS Healthy Start, HRP Household Reference Person Boldface indicates statistical significance ${ }^{*} P<0.05{ }^{*} P<0.01 * * P<0.001$

Model 1 - Adjusted for year + quarter

Model 2 - Adjusted for Model 1, household size, number of children $<1$ year, 0-3 years + age of HRP

Model 3 - Adjusted for Model 2, region, ethnicity, social class and education of HRP

a Sample of households with children $<1$ years $(n=1260)$

some inconsistencies [25, 26], evaluations of WIC report improved dietary intake [27-29] and infant health outcomes [30] in WIC participants compared to eligible non-participants. WIC participants are given access to a larger amount and wider variety of food than Healthy Start participants.

We did not find evidence of an association between Healthy Start participation and FV purchases. Economic theory suggests that a voucher will only increase the spending for households which previously spent less than the voucher value on target foods [18, 31]. Otherwise, the voucher will act as financial assistance, permitting money in the budget to be spent elsewhere. As the average spending on FV was above the voucher value for Eligible Non-participants ( $£ 4.5 /$ week [see Table 1]), it is unlikely that the voucher provided enough purchasing power to increase FV expenditure above usual levels in low-income households. Moreover, Healthy Start participants have reported using the vouchers as financial assistance $[13,15]$. In addition, the Healthy Start voucher has not changed value since 2010. Price inflation over this period may have exacerbated this issue and further undermined the voucher value. Price indices show that fruit and vegetable prices have increased by 46 and 31\% respectively between 2006 and 2017, while the value of Healthy Start vouchers increased by $11 \%$ [23]. A situation which is estimated to worsen due to Brexit [32]. As such, it is concerning that the voucher may have a further diminished value in the future. In response to this issue, the Scottish government raised the Healthy Start 


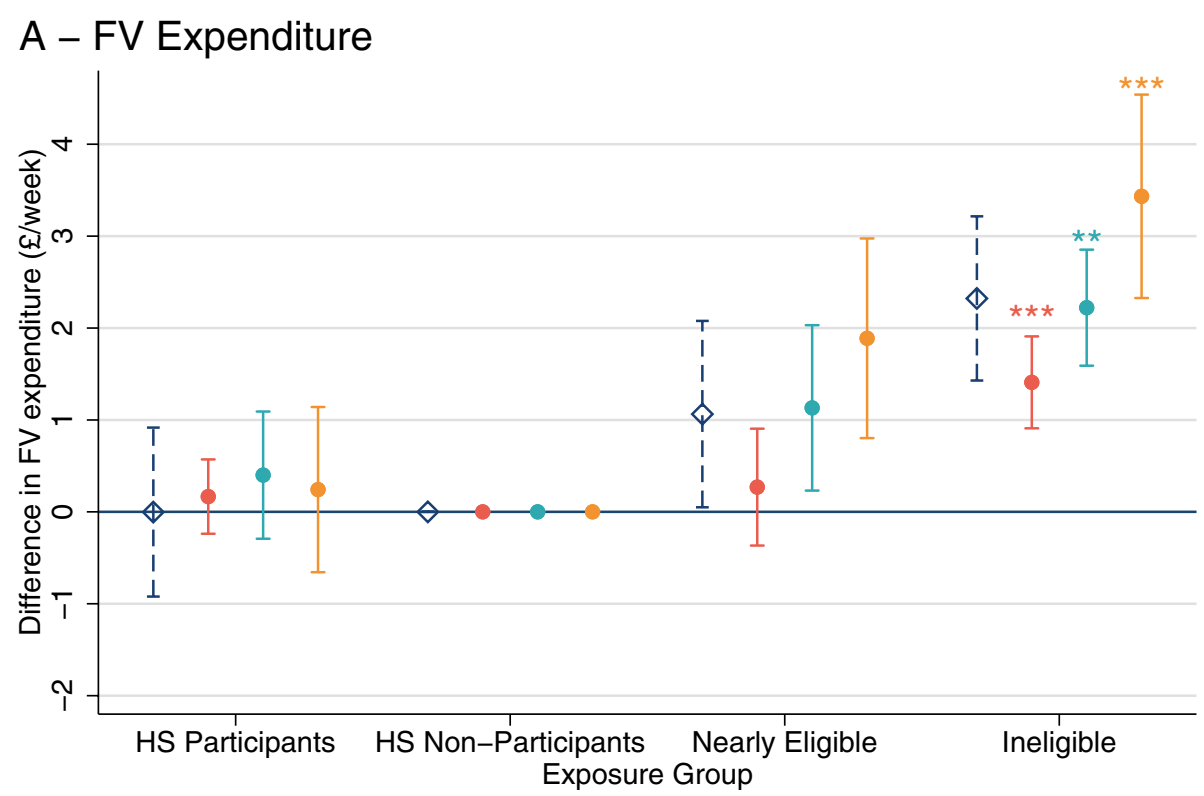

\section{B - FV Quantity}

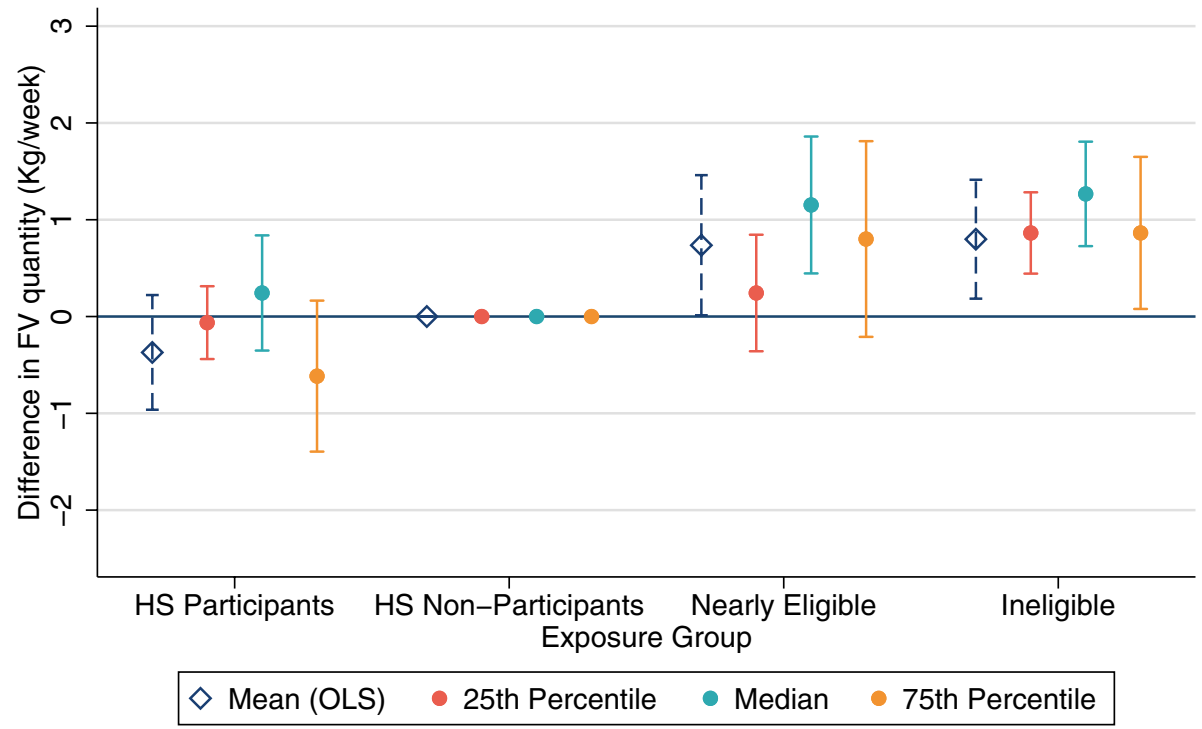

Fig. 1 Quantile regression of FV expenditure and quantity by Healthy Start participation. Footnotes: Significant difference between nearly eligible and ineligible groups using a Wald test ${ }^{*} P<0.05,{ }^{* *} P<0.01{ }^{* * *} P<0.001$. Models were adjusted by survey year, survey quarter, household size, number of children, age of HRP, ethnicity of HRP, NS-SEC social class, age HRP completed full-time education and region. FV- Fruit and vegetables; HS- Healthy Start; OLS- Ordinary Least Squares regression. A FV expenditure ( $£ /$ week) years 2010-17, n=4870; B FV quantity (Kg/week), years $2010-15, n=3265$

voucher value to $£ 4.25$ in August 2019, with the English government announcing the same for April 2021 [10, 33]. Increasing the benefit may enable Healthy Start participants to make a more meaningful change to their diet.

Health professionals have expressed concern that the inclusion of infant formula in the Healthy Start scheme may discourage breastfeeding [34]. In this analysis,
Healthy Start Participants purchased a significantly lower amount of infant formula compared to Eligible Nonparticipants, which could neither be explained by differences in total food expenditure nor differing prevalence of infants in the households. However, breastfeeding rates were unobserved thus could not be controlled for in this analysis. Findings from a Scottish longitudinal cohort 
suggest infant feeding practices were not significantly different between Healthy Start recipients and other nearly eligible mothers [35]. Together, these results could suggest Healthy Start does not disincentivise breast-feeding, however further investigation is needed to confirm this hypothesis.

An inequality in FV purchases was apparent between low-income and relatively higher-income households, reinforcing previous literature that income is associated with FV purchasing behaviours $[1,3]$. A higher quantity of FV purchased in Nearly Eligible households compared to Healthy Start Participants or Eligible Non-participants indicates that the programme may not mitigate even small income-inequalities. Future success of the programme could be determined by its ability to reduce the socioeconomic gradient in food purchases.

This study was novel in its ability to characterise Healthy Start Participants compared to Eligible Nonparticipants. We found that households with pregnant women were less likely to participate in the Healthy Start scheme. This is supported by qualitative research reporting poor awareness of the scheme amongst pregnant women [36]. A reliance on health professionals to promote the scheme has meant eligible pregnant women frequently learnt of the programme after birth. There have been no national-level campaigns to improve awareness, with local efforts targeting the eligible population. Improving universal awareness of the scheme has been suggested as a way of increasing uptake [14]. Moreover, the requirement for a health professional's signature was removed in April 2020 and the scheme is being digitised throughout 2021, which may help to improve future uptake of the scheme.

\section{Strengths and limitations}

The strengths of the present study are that it is the first to use a nationally representative dataset for the UK and observed participation in the Healthy Start scheme. We were able to accurately define a range of exposure groups due to the use of data containing detailed variables on household composition and income. Our results were also robust to a range of sensitivity analyses on the potential impacts of missing data.

The primary limitation is that the data were crosssectional, therefore change in participant's purchasing behaviours as a result of the vouchers could not be determined. Additionally, pooling years limited the ability to account for macroeconomic changes over time, although we did adjust for inflation and include year and quarter indicators in analyses to reduce potential biases. Additionally, as Healthy Start is targeted at very low-income households, the number of eligible households in nationally representative data was low. Resultantly, the analysis was underpowered to determine significance in small differences of FV expenditure. Finally, although participation in the scheme was self-reported, all reported incomes were confirmed with documentation, minimizing any potential misclassification bias.

\section{Conclusion}

In summary, our analysis did not provide evidence of different FV, Healthy Start foods or total food expenditure between Healthy Start participants and non-participants. The observed socioeconomic gradient in food spending reflects continuing inequalities in the UK. Our findings implicate that improvements to Healthy Start are needed for the programme to better serve the target population. Recent amendments to Healthy Start including simplifying the application (April 2020), increasing voucher value (April 2021) and introduction of an electronic card (2021) may provide the necessary changes to improve programme uptake and effectiveness. This study provides valuable shared lessons for similar food-assistance programs worldwide; iterative evaluations of food assistance programs are needed to ensure they dynamically meet the needs of low-income families.

\section{Abbreviations \\ UK: United Kingdom; FV: Fruit and vegetables; LCFS: Living Costs and Food Survey; OECD: Organisation for Economic Co-operation and Development; HRP: Household reference person; NS-SEC: National Statistics Socio-economic Classification; WIC: Special Supplemental Nutrition Program for Women, Infants and Children; OLS: Ordinary Least Squares; VIF: Variance inflation factor; HS: Healthy Start; SD: Standard deviation; Cl: Confidence interval; IQR: Inter- quartile Range; ANOVA: Analysis of variance.}

\section{Supplementary Information}

The online version contains supplementary material available at https://doi. org/10.1186/s12889-021-12222-5.

Additional file 1

\section{Acknowledgements}

The NIHR School for Public Health Research is a partnership between the Universities of Sheffield; Bristol; Cambridge; Imperial College London; and University College London; The London School for Hygiene and Tropical Medicine (LSHTM); LiLaC - a collaboration between the Universities of Liverpool and Lancaster; and Fuse - The Centre for Translational Research in Public Health a collaboration between Newcastle, Durham, Northumbria, Sunderland and Teesside Universities.

\section{Authors' contributions}

EPV, JPS, SVH and CM conceptualised the study. JCP, AL and EPV designed the study. SvH and KC advised on methods. JCP ran statistical analyses. All authors contributed to writing and approved final article. 


\section{Funding}

This study is funded by the National Institute for Health Research (NIHR) School for Public Health Research (Grant Reference Number PD-SPH-2015). The views expressed are those of the authors and not necessarily those of the NIHR or the Department of Health and Social Care.

\section{Availability of data and materials}

The datasets generated and/or analysed during the current study are available in the UK data service (GN 33334). Accessed from https://doi.org/10.5255/ UKDA-SN-8459-2

\section{Declarations}

\section{Ethics approval and consent to participate}

Imperial College Research Ethics Committee (ICREC) have confirmed that ethical approval was not required for this study. This study was a secondary analysis of a dataset accessed via the UK data service.

\section{Consent for publication}

Not applicable.

\section{Competing interests}

JP-S is vice-chair of the Royal Society for Public Health, Partner at Lane Clark \& Peacock LLP and reports personal fees from Novo Nordisk A/S all outside of the submitted work. All other authors have no competing interests. The funding body had no involvement in the design, analysis or writing of this study.

\section{Author details}

${ }^{1}$ Department of Primary Care, Public Health Policy Evaluation Unit, School of Public Health, Imperial College London, Charing Cross Campus, St Dunstans Road, London W6 8RP, UK. ${ }^{2}$ University of Bristol, Bristol, UK. ${ }^{3}$ Erasmus University Rotterdam, Rotterdam, The Netherlands. ${ }^{4}$ Institute for Fiscal Studies, London, UK. ${ }^{5}$ Department of Epidemiology and Biostatistics, School of Public Health, Imperial College London, London, UK. ${ }^{6} \mathrm{MRC}$ Centre for Environment and Health, Imperial College London, London, UK. ${ }^{7}$ Northumbria Healthcare NHS Foundation Trust, London, UK. ${ }^{8}$ Health Analytics, Lane Clark \& Peacock LLP, London, UK.

\section{Received: 9 July 2020 Accepted: 11 November 2021}

Published online: 17 December 2021

\section{References}

1. Yau A, Adams J, Monsivais P. Time trends in adherence to UK dietary recommendations and associated sociodemographic inequalities, 19862012: a repeated cross-sectional analysis. Eur J Clin Nutr. 2019. https://doi. org/10.1038/s41430-018-0347-z.

2. Steel N, Ford JA, Newton JN, Davis ACJ, Vos T, Naghavi M, et al. Changes in health in the countries of the UK and 150 English local authority areas 1990-2016: a systematic analysis for the global burden of disease study 2016. Lancet. 2018;392(10158):1647-61.

3. Mackenbach JD, Brage S, Forouhi NG, Griffin SJ, Wareham NJ, Monsivais P. Does the importance of dietary costs for fruit and vegetable intake vary by socioeconomic position? Br J Nutr. 2015;114(9):1464-70.

4. Darmon N, Drewnowski A. Contribution of food prices and diet cost to socioeconomic disparities in diet quality and health: a systematic review and analysis. Nutr Rev. 2015;73(10):643-60.

5. Friel S, Pescud M, Malbon E, Lee A, Carter R, Greenfield J, et al. Using systems science to understand the determinants of inequities in healthy eating. PLoS One. 2017;12(11):e0188872.

6. Headey DD, Alderman $\mathrm{HH}$. The relative caloric prices of healthy and unhealthy foods differ systematically across income levels and continents. J Nutr. 2019;149(11):2020-33.

7. Rao M, Afshin A, Singh G, Mozaffarian D. Do healthier foods and diet patterns cost more than less healthy options? A systematic review and meta-analysis. BMJ Open. 2013;3(12):e004277.

8. Department of Health. Healthy Start: Equality Impact Assessment 2010 [cited 201929 May]. Available from: https://webarchive.nationalarchives.
gov.uk/20101123083314/http://www.dh.gov.uk/en/Publichealth/Healt hyStart/index.htm.

9. Department of Health. Healthy Start NHS2018 [cited 201808 Oct]. Available from: https://www.healthystart.nhs.uk/for-health-professionals/.

10. Department for Work and Pensions. New winter package to provide further support for children and families 2020 [Available from: https:// www.gov.uk/government/news/new-winter-package-to-provide-furth er-support-for-children-and-families.

11. Healthy Start. Healthy Start uptake data (2015-2021). 2021. https://www. healthystart.nhs.uk/healthy-start-uptake-data/. Accessed 01 Mar 2021.

12. Crawley H, Dodds R. The UK healthy start scheme. What happened? What next? First Steps Nutrition Trust. 2018. https://www.firststepsnutrition. org/reports-gallery. Accessed 01 Mar 2021.

13. Lucas PJ, Jessiman T, Cameron A. Healthy start: the use of welfare food vouchers by low-income parents in England. Soc Policy Soc 2015;14(3):457-69.

14. McFadden A, Green JM, Williams V, McLeish J, McCormick F, Fox-Rushby J, et al. Can food vouchers improve nutrition and reduce health inequalities in low-income mothers and young children: a multi-method evaluation of the experiences of beneficiaries and practitioners of the healthy start programme in England. BMC Public Health. 2014;14(1):148.

15. Szpakowicz D. Evaluation of the Healthy Start Scheme: An Evidence Review Scotland: Scottish Government Social Research; 2016 [cited 2018 08 Oct]. Available from: https://www2.gov.scot/Publications/2016/03/ 7301/downloads\#res497237.

16. Ohly H, Crossland N, Dykes F, Lowe N, Moran VH. A realist qualitative study to explore how low-income pregnant women use Healthy Start food vouchers. 2019;15(1):e12632.

17. Scantlebury RJ, Moody A, Oyebode O, Mindell JS. Has the UK healthy start voucher scheme been associated with an increased fruit and vegetable intake among target families? Analysis of health survey for England data, 2001-2014. J Epidemiol Community Health. 2018;72(7):623-9.

18. Griffith R, von Hinke S, Smith S. Getting a healthy start: the effectiveness of targeted benefits for improving dietary choices. J Health Econ. 2018:58:176-87.

19. Living Costs and Food Survey 2017-2018. UK data service. 2019. https:// doi.org/10.5255/UKDA-SN-8459-2. Accessed 10 Mar 2019.

20. Office for National Statistics. Living Costs and Food Survey technical report: financial years ending March 2017 and March 2018 London: ONS; 2019 [cited 201926 Sep]. Available from: https://www.ons.gov.uk/peopl epopulationandcommunity/personalandhouseholdfinances/expen diture/methodologies/livingcostsandfoodsurveytechnicalreportfinanc ialyearendingmarch2017.

21. Department for Environment Food and Rural Affairs. Food Statistics in your pocket 2017: Prices and expenditure 2017 [Available from: https:// www.gov.uk/government/publications/food-statistics-pocketbook-2017/ food-statistics-in-your-pocket-2017-prices-and-expenditure.

22. Green R, Cornelsen L, Dangour AD, Turner R, Shankar B, Mazzocchi M, et al. The effect of rising food prices on food consumption: systematic review with meta-regression. BMJ (Clinical research ed). 2013;346:f3703.

23. Office for National Statistics. Inflation and price indices London: Office for National Statistics; 2019 [Available from: https://www.ons.gov.uk/econo my/inflationandpriceindices.

24. Koenker R, Hallock KF. Quantile Regression. J Econ Perspect. 2001;15(4):143-56

25. Vercammen KA, Moran AJ, Zatz LY, Rimm EB. 100\% juice, fruit, and vegetable intake among children in the special supplemental nutrition program for women, infants, and children and nonparticipants. Am J Prev Med. 2018;55(1):e11-e8.

26. Ng SW, Hollingsworth BA, Busey EA, Wandell JL, Miles DR, Poti JM. Federal Nutrition Program Revisions Impact low-income Households' food purchases. Am J Prev Med. 2018;54(3):403-12.

27. Tester JM, Leung CW, Crawford PB. Revised WIC food package and Children's diet quality. Pediatrics. 2016;137(5):e20153557.

28. Hamner HC, Paolicelli C, Casavale KO, Haake M, Bartholomew A. Food and beverage intake from 12 to 23 months by WIC status. Pediatrics. 2019;143(3):e20182274

29. Schultz DJ, Byker Shanks C, Houghtaling B. The impact of the 2009 special supplemental nutrition program for women, infants, and children food package revisions on participants: a systematic review. J Acad Nutr Diet. 2015:115(11):1832-46. 
30. Hamad R, Collin DF, Baer RJ, Jelliffe-Pawlowski LL. Association of Revised WIC food package with perinatal and birth outcomes: a quasi-experimental study Association of Revised WIC food package on perinatal and birth OutcomesAssociation of revised WIC food package on perinatal and birth outcomes. JAMA Pediatrics. 2019. https://doi.org/10.1001/jamap ediatrics.2019.1706.

31. Bitler MP, Seifoddini A. Health impacts of food assistance: evidence from the United States. Annu Rev Resour Econ. 2019;11(1):261-87.

32. Seferidi P, Laverty AA, Pearson-Stuttard J, Bandosz P, Collins B, GuzmanCastillo $M$, et al. Impacts of Brexit on fruit and vegetable intake and cardiovascular disease in England: a modelling study. BMJ Open. 2019;9(1):e026966.

33. Scottish parliament. The welfare foods (best start foods) (Scotland) Regulations 2019. 2019. https://www.legislation.gov.uk/ssi/2019/193/made. Accessed 01 Mar 2021.

34. McFadden A, Fox-Rushby J, Green JM, Pokhrel S, McLeish J, McCormick $F$, et al. Healthy start: understanding the use of vouchers and vitamins. Dundee: University of Dundee; 2013.

35. Boroujerdi M, Browne S, Wight D, Mcintosh E, Deidda M, Bradshaw P, et al. Evaluation of a voucher scheme for low income pregnant woman and mothers in the UK: Ruth Dundas [abstract]. Eur J Pub Health. 2017. https://doi.org/10.1093/eurpub/ckx189.168.

36. Browne S, Dundas R, Wight D. Assessment of the healthy start voucher scheme: a qualitative study of the perspectives of low income mothers. Lancet. 2016;388:S12.

\section{Publisher's Note}

Springer Nature remains neutral with regard to jurisdictional claims in published maps and institutional affiliations.

- fast, convenient online submission

- thorough peer review by experienced researchers in your field

- rapid publication on acceptance

- support for research data, including large and complex data types

- gold Open Access which fosters wider collaboration and increased citations

- maximum visibility for your research: over $100 \mathrm{M}$ website views per year

At BMC, research is always in progress.

Learn more biomedcentral.com/submissions 